\title{
Outcomes of urinary diversion after surgery for locally advanced or locally recurrent rectal cancer with complete cystectomy
}

Citation for published version (APA):

Hagemans, J. A. W., Voogt, E. L. K., Rothbarth, J., Nieuwenhuijzen, G. A. P., Kirkels, W. J., Boormans, J. L., Koldewijn, E. L., Richardson, R., Verhoef, C., Rutten, H. J. T., \& Burger, J. W. A. (2020). Outcomes of urinary diversion after surgery for locally advanced or locally recurrent rectal cancer with complete cystectomy: ileal and colon conduit. European Journal of Surgical Oncology, 46(6), 1160-1166. https://doi.org/10.1016/j.ejso.2020.02.021

Document status and date:

Published: 01/06/2020

DOI:

10.1016/j.ejso.2020.02.021

Document Version:

Publisher's PDF, also known as Version of record

\section{Document license:}

Taverne

Please check the document version of this publication:

- A submitted manuscript is the version of the article upon submission and before peer-review. There can be important differences between the submitted version and the official published version of record.

People interested in the research are advised to contact the author for the final version of the publication, or visit the DOI to the publisher's website.

- The final author version and the galley proof are versions of the publication after peer review.

- The final published version features the final layout of the paper including the volume, issue and page numbers.

Link to publication

\footnotetext{
General rights rights.

- You may freely distribute the URL identifying the publication in the public portal. please follow below link for the End User Agreement:

www.umlib.nl/taverne-license

Take down policy

If you believe that this document breaches copyright please contact us at:

repository@maastrichtuniversity.nl

providing details and we will investigate your claim.
}

Copyright and moral rights for the publications made accessible in the public portal are retained by the authors and/or other copyright owners and it is a condition of accessing publications that users recognise and abide by the legal requirements associated with these

- Users may download and print one copy of any publication from the public portal for the purpose of private study or research.

- You may not further distribute the material or use it for any profit-making activity or commercial gain

If the publication is distributed under the terms of Article $25 \mathrm{fa}$ of the Dutch Copyright Act, indicated by the "Taverne" license above, 


\title{
Outcomes of urinary diversion after surgery for locally advanced or locally recurrent rectal cancer with complete cystectomy; ileal and colon conduit
}

\author{
J.A.W. Hagemans ${ }^{\text {a, }}$, E.L.K. Voogt ${ }^{\text {b, }}{ }^{*}, 1$, J. Rothbarth ${ }^{\text {a }}$, G.A.P. Nieuwenhuijzen ${ }^{\text {b }}$, \\ W.J. Kirkels ${ }^{\text {c }}$, J.L. Boormans ${ }^{\text {c }}$, E.L. Koldewijn ${ }^{\mathrm{d}}$, R. Richardson ${ }^{\mathrm{d}}$, C. Verhoef ${ }^{\mathrm{a}}$, \\ H.J.T. Rutten ${ }^{\text {b, e }}$, J.W.A. Burger ${ }^{b}$ \\ a Department of Surgical Oncology, Erasmus MC Cancer Institute, Rotterdam, the Netherlands \\ b Department of Surgery, Catharina Hospital Eindhoven, Eindhoven, the Netherlands \\ c Department of Urology, Erasmus MC Cancer Institute, Rotterdam, the Netherlands \\ d Department of Urology, Catharina Hospital Eindhoven, Eindhoven, the Netherlands \\ e School for Oncology and Developmental Biology (GROW), Maastricht University, Maastricht, the Netherlands
}

\section{A R T I C L E I N F O}

\section{Article history:}

Received 10 September 2019

Received in revised form

13 February 2020

Accepted 17 February 2020

Available online 20 February 2020

\section{Keywords:}

Pelvic exenteration

Rectal cancer

Urinary diversion

Ileal conduit

Colon conduit

\begin{abstract}
A B S T R A C T
Introduction: Surgery for locally advanced rectal cancer (LARC) or locally recurrent rectal cancer (LRRC) may require total pelvic exenteration with the need for urinary diversion. The aim of this study was to describe outcomes for ileal and colon conduits after surgery for LARC and LRRC.

Methods: All consecutive patients from two tertiary referral centers who underwent total pelvic exenteration for LARC or LRRC between 2000 and 2018 with cystectomy and urinary reconstruction using an ileal or colon conduit were retrospectively analyzed. Short- ( $\leq 30$ days) and long-term ( $>30$ days) complications were described for an ileal and colon conduit.

Results: 259 patients with LARC $(\mathrm{n}=131)$ and LRRC $(\mathrm{n}=128)$ were included, of whom 214 patients received an ileal conduit and 45 patients a colon conduit. Anastomotic leakage of the ileo-ileal anastomosis occurred in 9 patients (4\%) after performing an ileal conduit. Ileal conduit was associated with a higher rate of postoperative ileus ( $21 \% \mathrm{vs} 7 \%, \mathrm{p}=0.024$ ), but a lower proportion of wound infections than a colon conduit ( $14 \%$ vs $31 \%, \mathrm{p}=0.006$ ). The latter did not remain significant in multivariate analysis. No difference was observed in the rate of uretero-enteric anastomotic leakage, urological complications, mortality rates, major complications (Clavien-Dindo $\geq 3$ ), or hospital stay between both groups.

Conclusion: Performing a colon conduit in patients undergoing total pelvic exenteration for LARC or LRRC avoids the risks of ileo-ileal anastomotic leakage and may reduce the risk of a post-operative ileus. Besides, there are no other differences in outcome for ileal and colon conduits.
\end{abstract}

๑) 2020 Elsevier Ltd, BASO The Association for Cancer Surgery, and the European Society of Surgical Oncology. All rights reserved.

\section{Introduction}

In approximately $10 \%$ of all newly diagnosed patients with primary rectal cancer there is local invasion of the tumor in surrounding structures. In patients who develop a local recurrence, which occurs in approximately $6-10 \%$ of all patients treated for

* Corresponding author. Department of Surgery, Catharina Hospital Eindhoven, P.O. Box 1350, 5602 ZA, Eindhoven, the Netherlands.

E-mail address: eva.voogt@catharinaziekenhuis.nl (E.L.K. Voogt).

1 Both authors equally contributed to this manuscript. primary rectal cancer, invasion in adjacent organs, such as the bladder and/or the organs of the reproductive system, is even more common [1-3]. Radical surgery is essential for cure and the achievement of a clear resection margin is the most important prognostic factor for overall survival in these patients [4,5]. To achieve a clear resection margin in patients with tumor invasion in the bladder, prostate or urethra, a radical approach is indicated, which often requires partial or complete cystectomy (i.e. pelvic exenteration). When a complete cystectomy is performed patients require a urinary diversion [6,7]. Historically there are several urinary diversions, but in current practice the most common urinary 
diversions are an ileal conduit (i.e. Bricker) or a colon conduit [8-11]. In both cases an isolated bowel segment (ileum or colon) is used as a conduit for the ureters, which is deviated through the abdominal wall as a urostomy. Both surgical procedures slightly differ due to the use of different bowel segments. An ileal conduit requires an ileo-ileal anastomosis, whereas in colon conduits an extra anastomosis is usually not required because the terminal segment of the descending colon can be used. Both procedures are associated with general surgical and urological complications. In addition, conduit specific complications may occur, such as metabolic changes or intra-abdominal complications of the urinary diversion, such as leakage of the uretero-entero anastomosis and ileus $[8,12-14]$.

The aim of this study was to describe the short- and long-term complications associated with an ileal and colon conduit after surgery for locally advanced rectal cancer (LARC) and locally recurrent rectal cancer (LRRC) in a pooled cohort of two large tertiary referral hospitals.

\section{Patient and methods}

All consecutive patients who underwent a total pelvic exenteration with complete cystectomy for LARC or LRRC with formation of an ileal or colon conduit in the Catharina Hospital Eindhoven (CZE) or the Erasmus MC Cancer Institute (EMC) between January 2000 and November 2018, were identified from a prospectively maintained database. CZE and EMC are both tertiary referral hospitals in the Netherlands. Both centers have an experienced multidisciplinary tumor board (MDT) in which all patients diagnosed with rectal cancer are discussed and evaluated for optimal multimodality treatment. This tumor board includes dedicated surgeons, radiologists, radiation oncologists, medical oncologists and urologists. If indicated, gynecologists, pathologists and plastic surgeons participate in this meeting.

\section{Data collection}

All data on patient and tumor characteristics, (neo)adjuvant treatment, surgical procedures, perioperative variables, short- and long-term surgical and urological outcomes were retrospectively reviewed. All included patients were followed up for at least 30 days after surgery. Thereafter, follow-up was either conducted in the hospital in which the surgery was performed or in the patients' primary referring hospital. The present study was approved by both institutional local medical ethics committees (CZE; registration number: W19.031 and EMC registration number; MEC-2017-448).

\section{Neoadjuvant treatment and surgical procedures}

Patients were usually scheduled for neoadjuvant radiotherapy: short-course (25Gy) or long-course (50Gy) radiotherapy for LARC and re-irradiation (30Gy) or long course (50Gy) for LRRC, either with or without concurrent chemotherapy. Surgery was performed in collaboration with the surgical oncologist and urologist. Resection of the rectal tumor was performed by open abdominal or abdominoperineal approach. All patients underwent a complete cystectomy and a urinary diversion was performed by ileal or colon conduit. The surgical procedures were similar in both CZE and EMC, except for the administration of intra-operative radiation therapy (IORT) that was delivered as intra-operative external beam radiotherapy (IOERT) in the CZE and as intra-operative brachytherapy (IOBT) in the EMC. In the EMC, the choice for either a colon conduit or an ileal conduit was made during surgery and was based on practical considerations; there were no reasons for choosing one technique or the other from an oncological perspective. A colon conduit was the preferred technique when this would avoid the need to make an extra anastomosis. In practice, this meant that patients who were to receive an end colostomy were selected for the colon conduit technique. In case a primary low anastomosis could be performed or a colon conduit could not prevent an extra anastomosis, an ileal conduit was routinely performed. In the CZE, the preferred method was to perform an ileal conduit.

An ileal conduit was performed as previously described by Bricker et al. In summary, an ileal segment of approximately $15 \mathrm{~cm}$ was isolated at $10 \mathrm{~cm}$ distance from the valve of Bauhin, and a hand sewed or stapled ileo-ileal anastomosis was performed [9]. Both ureters were spatulated and then separately hand sutured in one layer with PDS 4-0 side-to-end into the ileal segment. Subsequently, the distal end of the conduit was delivered through the abdominal wall and was matured.

To create a colon conduit a colon segment of approximately $15 \mathrm{~cm}$ was isolated [10]. This segment was the distal segment of the descending colon that was already transected during a procedure in which the rectum was removed. Oxygenation of this segment was supplied by the left colonic artery, which means that a low tie of the inferior mesenteric artery was performed for the rectal resection. The colon conduit was often placed in the left hemiabdomen and the transverse colon was then mobilized to create a right-sided end colostomy, although colon conduits are usually mobile enough to facilitate placement on either side of the abdomen (Fig. 1). In some cases, the ureters were inserted in an already existing colostomy after which a new end colostomy was created for stool. Ureters were attached in the same way as described for Bricker's diversion. In both ileal and colon conduits single J stents (EMC 7 French and CZE 8 French) were placed in both ureters to ensure sufficient flow during the first 10 days. Stents were fixed to the bowel wall with 40 quickly absorbable braided sutures and led out through the ostomy. If no complications occurred stents were removed at day 9 and day 10 after surgery under antibiotic prophylaxis.

\section{Complications}

Short-term complications were defined as any complication within 30 days after surgery, during the primary hospital admission or during a readmission within 30 days. Long-term complications were defined as any complication that occurred more than 30 days after surgery, unless they occurred during the primary admission or a readmission within 30 days. Complications were graded according to the Clavien-Dindo classification [15]. Surgical and urological complications were identified from available data. Urological complications were defined as complications related to the urinary diversion or urogenitary tract or the ileo-ileal anastomosis performed for isolating the ileal conduit. Surgical complications were defined as any non-urological complication. A postoperative ileus was defined as two or more of the following: nausea/vomiting, inability to tolerate an oral diet, the absence of flatus, abdominal distention and/or radiological evidence of bowel distension without signs of a mechanical obstruction. During hospitalization, patients were daily observed for the occurrence of ileus. An anastomotic leakage was defined as a communication between the intra- and extraluminal compartments, determined by either clinical or radiologic evidence.

\section{Statistical analysis}

Continuous data were reported as median (interquartile range or $95 \%$ confidence interval) and categorical data were reported as count (percentage). Group comparisons were made using Chisquare or Mann-Whitney $U$ test as appropriate. Long-term complication rates were calculated from the date of surgery until 

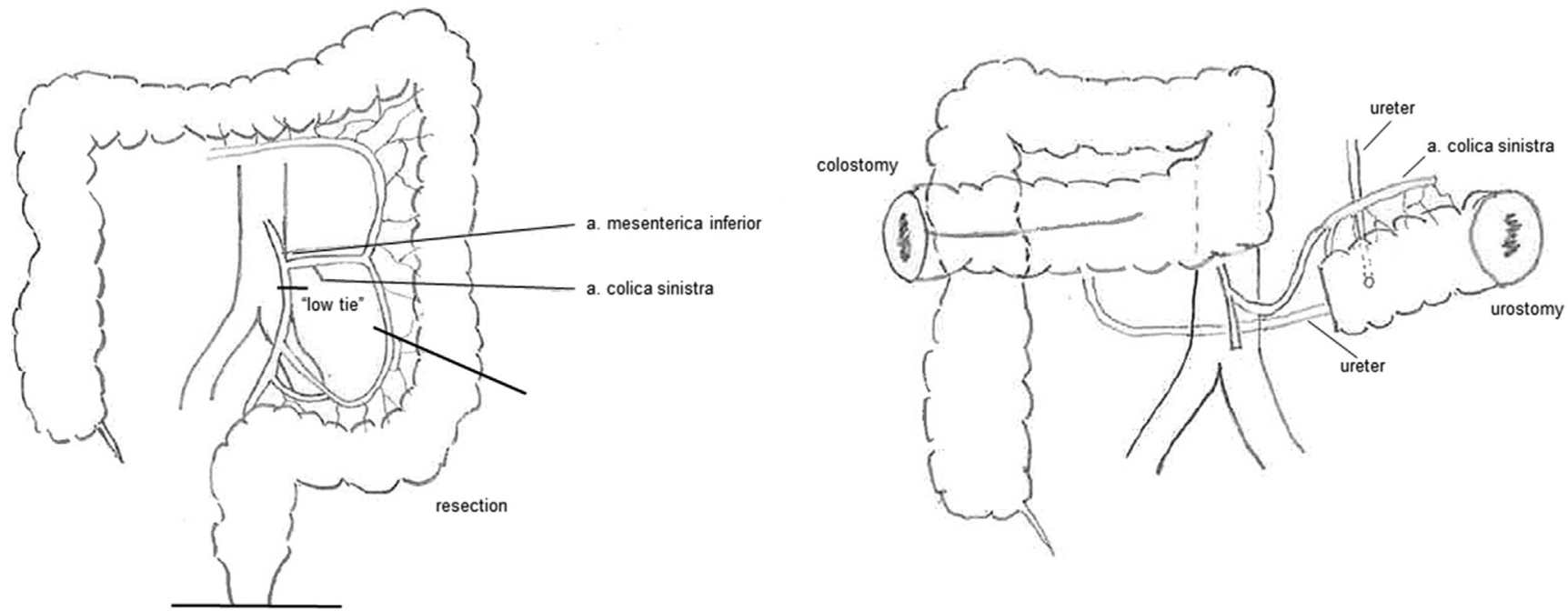

Fig. 1. Schematic presentation of performing a colon conduit.

Table 1

Baseline characteristics colon conduit vs ileal conduit.

\begin{tabular}{|c|c|c|c|c|c|}
\hline & & \multirow{2}{*}{$\frac{\text { Total }(\mathrm{N}=259)}{\mathrm{N}(\%)}$} & \multirow{2}{*}{$\frac{\text { Colon conduit }(\mathrm{N}=45)}{\mathrm{N}(\%)}$} & \multirow{2}{*}{$\frac{\text { Ileal conduit }(\mathrm{N}=214)}{\mathrm{N}(\%)}$} & \multirow[t]{2}{*}{ P-value } \\
\hline & & & & & \\
\hline \multirow[t]{2}{*}{ Hospital } & CZE & $134(52)$ & $1(2)$ & $133(62)$ & $<0.001$ \\
\hline & EMC & $125(48)$ & $44(98)$ & $81(38)$ & \\
\hline \multirow[t]{2}{*}{ Type of rectal cancer } & LARC & $131(50)$ & $28(62)$ & $103(48)$ & 0.086 \\
\hline & LRRC & $128(50)$ & $17(38)$ & $111(52)$ & \\
\hline \multirow[t]{2}{*}{ Gender } & Female & $45(17)$ & $7(16)$ & $38(18)$ & 0.723 \\
\hline & Male & $214(83)$ & $38(84)$ & $176(82)$ & \\
\hline Age at resection & Median [IQR] & $66.0[58.0,70.5]$ & $66.0[58.0,70.0]$ & $66.0[58.0,70.8]$ & 0.937 \\
\hline \multirow[t]{3}{*}{ ASA } & I & $42(17)$ & $7(16)$ & $35(18)$ & 0.944 \\
\hline & II & $164(67)$ & $31(69)$ & $133(67)$ & \\
\hline & III & $37(15)$ & $7(16)$ & $30(15)$ & \\
\hline \multirow[t]{2}{*}{ Clinical tumor stage $\mathrm{e}^{\mathrm{a}}$} & сT3 & $12(9)$ & $2(7)$ & $10(10)$ & 0.676 \\
\hline & cT4 & $119(91)$ & $26(93)$ & $93(90)$ & \\
\hline \multirow[t]{3}{*}{ Clinical nodal stage } & $\mathrm{cNO}$ & $70(46)$ & $13(37)$ & $57(48)$ & 0.144 \\
\hline & $\mathrm{cN} 1$ & $34(22)$ & $12(34)$ & $22(19)$ & \\
\hline & $\mathrm{cN} 2$ & $49(32)$ & $10(29)$ & $39(33)$ & \\
\hline \multirow[t]{2}{*}{ Clinical metastases } & cM0 & $229(88)$ & $38(84)$ & $191(89)$ & 0.360 \\
\hline & cM1 & $30(12)$ & $7(16)$ & $23(11)$ & \\
\hline \multirow[t]{2}{*}{ Neoadjuvant chemotherapy } & No & $213(82)$ & $40(89)$ & $173(81)$ & 0.199 \\
\hline & Yes $^{b}$ & $46(18)$ & $5(11)$ & $41(19)$ & \\
\hline \multirow[t]{3}{*}{ Neoadjuvant radiotherapy } & None & $25(9)$ & $4(9)$ & $21(10)$ & 0.113 \\
\hline & Radiotherapy & $51(20)$ & $4(9)$ & $47(22)$ & \\
\hline & Chemoradiotherapy & $182(71)$ & $37(82)$ & $145(68)$ & \\
\hline Interval radiotherapy - surgery (weeks) & Median [IQR] & $11.0[9.0,15.0]$ & $13.0[10.0,14.0]$ & $11.0[9.0,15.0]$ & 0.314 \\
\hline
\end{tabular}

CZE: Catharina Hospital Eindhoven; EMC: Erasmus Medical Center; LARC: Locally advanced rectal cancer; LRRC: Locally recurrent rectal cancer.

a Only applicable for LARC.

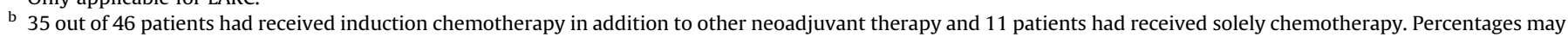
not add up to $100 \%$ due to rounding.

the last visit to the outpatient clinic. Two-sided p-values $\leq 0.05$ were considered statistically significant. Multivariable logistic regression analysis was performed using all variables from Table 1 and Table 2 with a p-value $<0.1$. Nephrectomy was not used as a covariable in multivariable analysis due to low patient numbers. Statistical analyses were performed using SPSS version 24.0 (SPSS Inc., Chicago, IL) and R version 3.5.1 (http://www.r-project.org).

\section{Results}

Baseline characteristics are shown in Table 1. A total of 259 patients with locally advanced $(\mathrm{n}=131$ ) or locally recurrent rectal cancer $(n=128)$ were included for analyses. An ileal conduit was performed in 214 patients and more frequently in the CZE (CZE $\mathrm{n}=133, \mathrm{EMC}=81$ ) and a colon conduit in 45 patients and more frequently in the EMC $($ CZE $n=1, E M C n=44)(p<0.001)$. No other significant baseline differences were observed.

\section{Surgical results}

Surgical characteristics are shown in Table 2. All patients underwent pelvic exenteration with a cystectomy and resection of the (recurrent) rectal tumor. The length of the conduit was similar for both ileal and colon conduit (median $15 \mathrm{~cm}$, IQR 15-20 cm). Patients with a colon conduit more often received an end colostomy, whereas patients with an ileal conduit more often had an ostomy from previous surgery (e.g. end colostomy after resection for the primary tumor $)(\mathrm{p}=0.040)$. Colo-anal anastomoses were more often performed in patients with an ileal conduit $(p=0.027)$. The operation time was significantly shorter for patients receiving an 
Table 2

Surgical results colon conduit vs ileal conduit.

\begin{tabular}{|c|c|c|c|c|c|}
\hline & & Total $(\mathrm{N}=259)$ & Colon conduit $(\mathrm{N}=45)$ & Ileal conduit $(\mathrm{N}=214)$ & P-value \\
\hline & & $\mathrm{N}(\%)$ & $\mathrm{N}(\%)$ & $\mathrm{N}(\%)$ & \\
\hline \multirow[t]{2}{*}{ Approach } & Abdominal & $109(42)$ & $19(42)$ & $90(42)$ & 0.984 \\
\hline & Abdominoperineal & $150(58)$ & $26(58)$ & $124(58)$ & \\
\hline HIPEC & Yes & $5(2)$ & $0(0)$ & $5(2)$ & 0.300 \\
\hline Synchronous metastases resection ${ }^{\mathrm{a}}$ & Yes & $8(27)$ & $3(43)$ & $5(22)$ & 0.269 \\
\hline \multirow[t]{3}{*}{ IORT } & IOBT & $41(16)$ & $16(36)$ & $25(12)$ & $<0.001$ \\
\hline & IOERT & $105(41)$ & $1(2)$ & $104(49)$ & \\
\hline & No & $113(44)$ & $28(62)$ & $85(40)$ & \\
\hline Ureter resection & Yes & $2(1)$ & $0(0)$ & $2(1)$ & NA \\
\hline Nephrectomy & Yes & $3(2)$ & $1(1)$ & $2(1)$ & 0.075 \\
\hline Length conduit $(\mathrm{cm})$ & Median [IQR] & $15.0[15.0,20.0]$ & $15.0[15.0,20.0]$ & $15.0[15.0,20.0]$ & 0.372 \\
\hline \multirow[t]{2}{*}{ Ileo-ileal anastomosis for ileal conduit } & No & NA & NA & $4(2)$ & NA \\
\hline & Yes & NA & NA & $210(98)$ & \\
\hline \multirow[t]{2}{*}{ Colo-anal anastomosis } & No & $228(88)$ & $44(98)$ & $184(86)$ & 0.027 \\
\hline & Yes & $31(12)$ & $1(2)$ & $30(14)$ & \\
\hline \multirow[t]{2}{*}{ Additional anastomosis } & No & $240(93)$ & $43(96)$ & $197(92)$ & 0.413 \\
\hline & Yes & $19(7)$ & $2(4)$ & $17(8)$ & \\
\hline \multirow[t]{4}{*}{ Ostomy } & No ostomy & $4(2)$ & $0(0)$ & $4(2)$ & 0.040 \\
\hline & Pre-existing ostomy & $101(39)$ & $13(29)$ & $88(41)$ & \\
\hline & Loop ostomy & $29(11)$ & $2(4)$ & $27(13)$ & \\
\hline & End ostomy & $125(48)$ & $30(67)$ & $95(44)$ & \\
\hline Blood loss (ml) & Median [IQR] & $3200.0[2125.0,5500.0]$ & $3000.0[2200.0,3600.0]$ & $3400.0[2100.0,6625.0]$ & 0.088 \\
\hline Operation time (min) & Median [IQR] & $437.0[362.5,517.2]$ & $510.0[439.0,620.0]$ & $420.0[351.0,495.0]$ & $<0.001$ \\
\hline
\end{tabular}

NA: Not applicable; HIPEC: Hyperthermic intraperitoneal chemotherapy; IORT: Intra-operative radiation therapy.

IOBT: intra-operative brachytherapy; IOERT: intra-operative external beam radiotherapy.

a Calculated as percentage of patients with synchronous metastases. Percentages may not add up to $100 \%$ due to rounding.

ileal conduit than for those receiving a colon conduit with 420 min [IQR 351-495 $\mathrm{min}$ ] versus $510 \mathrm{~min}$ [IQR 439-620], respectively $(\mathrm{p}<0.001)$.

\section{Anastomosis}

In 210/214 patients with an ileal conduit an ileo-ileal anastomosis was performed, and in four patients no anastomosis was required because the pre-existing end ileostomy was used as a conduit $(n=1)$ or a new end ileostomy was performed $(n=3)$. In 30 patients with an ileal conduit a colo-anal anastomosis was performed, and in 17 patients an additional anastomosis was performed due to an additional bowel resection. In patients with a colon conduit, one colo-anal anastomosis was performed and two additional anastomoses due to an additional bowel resection were performed.

\section{Short-term surgical and urological complications}

Short-term surgical and urological complications are displayed in Tables 3 and 4. There was no statistical difference in major complications (Clavien-Dindo $\geq 3$ ) and mortality rates (30-day mortality or in-hospital mortality) for patients with an ileal conduit compared to a colon conduit. There was no difference between hospital stay, reintervention rates and readmission rates between both groups. A postoperative ileus occurred more often in patients with an ileal conduit compared to patients with a colon conduit ( 21 vs. $7 \%, \mathrm{p}=0.024$, respectively), which remained significant after multivariable analysis $(\mathrm{p}=0.025)$. In patients with a colon conduit a wound infection (perineal and/or abdominal) was observed more often than in patients with an ileal conduit (31\% vs. $16 \%, \mathrm{p}=0.006$ ), but this was not significant after multivariable analysis ( $\mathrm{p}=0.37$ ). No significant differences were found when comparing the rate of urological complications or the reintervention rate for urologic complications between the two groups. Metabolic acidosis occurred in 6 patients (3\%) with an ileal conduit, and did not occur in patients with a colon conduit ( $\mathrm{p}=0.256$ ).
Anastomotic leakage occurred in $6 / 210$ patients (3\%) with an ileo-ileal anastomosis. Anastomotic leakage of the ureter anastomosis occurred in 14/214 patients (7\%) with an ileal conduit and in $3 / 45$ patients $(7 \%)$ with a colon conduit $(\mathrm{p}=0.976)$. Anastomotic leakage of the colo-anal anastomosis occurred in $7 / 30$ patients (23\%) with an ileal conduit. In the colon conduit group only one colo-anal anastomosis was performed without leakage. In both groups, no leakage of additional anastomoses was observed.

When comparing only patients who underwent a resection through abdominoperineal approach, a postoperative ileus was still more often observed in patients who received an ileal conduit compared with a colon conduit $(\mathrm{p}=0.028)$. The wound infection rate did not differ. In a subanalysis comparing patients with LARC and LRRC, there were no significant differences in short-term surgical and urologic complications.

\section{Long-term complications}

Long-term complications are presented in Table 5 . In $72 \%$ of the patients (186 patients, colon conduit $\mathrm{n}=44$, ileal conduit $\mathrm{n}=142$ ) long term complications after 30 days were registered. The median follow-up for survivors for long-term complications was 55 months (95\% CI 55-65 months). No significant differences in long-term complications between both groups were observed. One patient (2\%) with a colon conduit and five patients (4\%) with an ileal conduit experienced metabolic acidosis $(\mathrm{p}=0.582)$. Three $(2 \%)$ out of 139 patients with an ileal conduit presented with a late anastomotic leakage of the ileo-ileal anastomosis, 2/142 patients (1\%) with uretero-ileal conduit leakage, and 2/21 patients (9\%) with leakage of the colo-anal anastomosis. Patients with a colon conduit did not experience anastomotic leakage 30 days after surgery. Twelve patients ( $9 \%$ ) with an ileal conduit developed a fistula ( $\mathrm{n}=8$ entero-cutaneous, $\mathrm{n}=4$ uretero-enteric) compared to four $(9 \%)$ patients with a colon conduit ( $\mathrm{p}=0.895$ ) (all entero-cutaneous). In a subanalysis, there were no significant differences in long-term surgical and urologic complications when comparing LARC with LRRC. 
Table 3

Short-term general and surgical complications colon conduit vs ileal conduit.

\begin{tabular}{|c|c|c|c|c|}
\hline & Total $(\mathrm{N}=259)$ & Colon conduit $(\mathrm{N}=45)$ & Ileal conduit $(\mathrm{N}=214)$ & P-value \\
\hline & $\mathrm{N}(\%)$ & $\mathrm{N}(\%)$ & $\mathrm{N}(\%)$ & \\
\hline 30-day mortality & $14(5)$ & $1(2)$ & $13(6)$ & 0.299 \\
\hline In-hospital mortality & $26(10)$ & $3(7)$ & $23(11)$ & 0.408 \\
\hline Major complications (Clavien-Dindo $\geq 3$ ) & $101(39)$ & $14(31)$ & $87(41)$ & 0.233 \\
\hline Any reintervention & $90(35)$ & $11(24)$ & $79(37)$ & 0.110 \\
\hline Ileus & $48(19)$ & $3(7)$ & $45(21)$ & 0.024 \\
\hline Wound infection (abdominal \& perineal) & $44(17)$ & $14(31)$ & $30(14)$ & 0.006 \\
\hline Pre-sacral abscess & $47(18)$ & $7(16)$ & 40 (19) & 0.620 \\
\hline Abdominal abscess & $31(12)$ & $4(9)$ & $27(13)$ & 0.484 \\
\hline Ostomy complication & $4(2)$ & $0(0)$ & $4(2)$ & 0.355 \\
\hline Fistula & $6(2)$ & $1(2)$ & $5(2)$ & 0.963 \\
\hline Hospital stay in days (median [IQR]) & $14.0[11.0,18.5]$ & $13.0[11.0,19.0]$ & $14.0[10.0,18.0]$ & 0.859 \\
\hline No readmission & $217(83)$ & $36(80)$ & $179(84)$ & 0.230 \\
\hline Urological readmission & $11(4)$ & $4(9)$ & $7(3)$ & \\
\hline Non-urological readmission & $33(13)$ & $5(11)$ & $28(13)$ & \\
\hline
\end{tabular}

Percentages may not add up to $100 \%$ due to rounding.

Table 4

Short-term urological complications colon conduit vs ileal conduit.

\begin{tabular}{|c|c|c|c|c|}
\hline & Total $(\mathrm{N}=259)$ & Colon conduit $(\mathrm{N}=45)$ & Ileal conduit $(\mathrm{N}=214)$ & P-value \\
\hline & $\mathrm{N}(\%)$ & $\mathrm{N}(\%)$ & $\mathrm{N}(\%)$ & \\
\hline Urological complication & $58(22)$ & $7(16)$ & $51(24)$ & 0.226 \\
\hline Urological reintervention & $35(14)$ & $4(9)$ & $31(14)$ & 0.318 \\
\hline Urosepsis & $9(3)$ & $1(2)$ & $8(4)$ & 0.614 \\
\hline Metabolic acidosis & $6(2)$ & $0(0)$ & $6(3)$ & 0.256 \\
\hline Urinoma & $12(5)$ & $2(4)$ & $10(5)$ & 0.947 \\
\hline Urinoma drainage & $9(3)$ & $2(4)$ & $7(3)$ & 0.696 \\
\hline Urostomy complication & $4(2)$ & $1(2)$ & $3(1)$ & 0.685 \\
\hline Hydronefrosis & $22(8)$ & $1(2)$ & $21(10)$ & 0.097 \\
\hline Ureter stenosis & $7(3)$ & $0(0)$ & $7(3)$ & 0.609 \\
\hline Urinary tract infection & $16(6)$ & $3(7)$ & $13(6)$ & 0.881 \\
\hline Leakage ileo-ileal anastom & & & & \\
\hline No & NA & NA & $204(97)$ & NA \\
\hline Yes & NA & NA & $6(3)$ & \\
\hline Leakage ureter - conduit a & & & & \\
\hline No & $242(93)$ & $42(93)$ & $200(93)$ & 0.976 \\
\hline Yes & $17(7)$ & $3(7)$ & $14(7)$ & \\
\hline Leakage colo-anal anaston & & & & \\
\hline No & $24(77)$ & $1(100)$ & $23(77)$ & 0.538 \\
\hline Yes & $7(23)$ & $0(0)$ & $7(23)$ & \\
\hline Leakage other anastomosi & & & & \\
\hline No & $19(100)$ & $2(100)$ & $17(100)$ & NA \\
\hline Yes & $0(0)$ & $0(0)$ & $0(0)$ & \\
\hline
\end{tabular}

NA: Not applicable.

Percentages may not add up to $100 \%$ due to rounding.

a Percentage of anastomotic leakage is calculated of patients in which a specific anastomosis was performed.

\section{Discussion}

The present pooled retrospective cohort of 259 patients undergoing total pelvic exenteration with urinary diversion for LARC and LRRC describes few differences in surgical and urological complications between a colon conduit and an ileal conduit. However, the formation of a colon conduit avoids the risk of ileoileal anastomotic leakage, which was $4 \%$ in this cohort. In addition, an ileal conduit appears to be associated with a higher postoperative ileus rate.

Several studies reported on outcomes after multivisceral surgery with cystectomy and the formation of a urinary diversion. However, complications are usually described for all types of pelvic cancer, and as outcomes may differ for different types of cancer this complicates comparison between studies. In the case of LARC and LRRC, a complete en bloc bladder removal with the rectal tumor is often performed, which makes it prone to other complications than after primary cystectomy alone [16,17]. A recent study by
Bolmstrand et al. described complications after urinary tract reconstruction in colorectal and anal cancer after partial or complete cystectomy [13]. They reported a rate of 35\% major complications (Clavien-Dindo $\geq 3$ ), which is comparable with the $39 \%$ in our series. The rate of intestinal anastomotic leakage was $9 \%$ in their series compared to $7 \%$ in our study. In the present study we did not find a significant difference when comparing the anastomotic leakages separately between the two types of conduit. However, 9 patients with an ileal conduit had an anastomotic leakage of the ileo-ileal anastomosis which is obviously ruled out when a colon conduit is performed.

Teixeira et al. compared outcomes in 74 patients who received an ileal or a colon conduit for different types of pelvic malignancies [12]. Their study did not find significant differences for complications assessed separately, such as urinary leaks, small bowel fistula, sepsis or drained collections. However, when all complications were combined, a significantly higher incidence of complications in patients with an ileal conduit compared to a colon conduit was 
Table 5

Long-term complications colon conduit vs ileal conduit.

\begin{tabular}{|c|c|c|c|c|}
\hline & \multirow{2}{*}{$\frac{\text { Total }(\mathrm{N}=186)}{\mathrm{N}(\%)}$} & \multirow{2}{*}{$\frac{\text { Colon conduit }(\mathrm{N}=44)}{\mathrm{N}(\%)}$} & \multirow{2}{*}{$\frac{\text { Ileal conduit }(\mathrm{N}=142)}{\mathrm{N}(\%)}$} & \multirow[t]{2}{*}{ P-value } \\
\hline & & & & \\
\hline Urological complication & $37(20)$ & $6(14)$ & $31(22)$ & 0.234 \\
\hline Urological reintervention & $22(12)$ & $5(11)$ & $17(12)$ & 0.913 \\
\hline Urosepsis & $4(2)$ & $1(2)$ & $3(2)$ & 0.949 \\
\hline Metabolic acidosis & $6(3)$ & $1(2)$ & $5(4)$ & 0.682 \\
\hline Hydronefrosis & $19(10)$ & $3(7)$ & $16(11)$ & 0.394 \\
\hline Percutaneous nephrostomy drainage & $14(7)$ & $2(5)$ & $12(9)$ & 0.319 \\
\hline Urinary tract infection & $19(10)$ & $4(9)$ & $15(11)$ & 0.778 \\
\hline Urinoma & $0(0)$ & $0(0)$ & $0(0)$ & NA \\
\hline Ureter stenosis & $16(9)$ & $4(9)$ & $12(9)$ & 0.895 \\
\hline Revision ureter stenosis & $3(2)$ & $2(5)$ & $1(1)$ & 0.076 \\
\hline Revision urostomy & $4(2)$ & $2(5)$ & $2(1)$ & 0.207 \\
\hline Fistula & $16(9)$ & $4(9)$ & $12(9)$ & 0.895 \\
\hline \multicolumn{5}{|l|}{ Leakage ileo-ileal anastomosis ${ }^{\mathrm{a}}$} \\
\hline No & NA & NA & $136(98)$ & NA \\
\hline Yes & NA & NA & $3(2)$ & \\
\hline \multicolumn{5}{|l|}{ Leakage ureter - conduit anastomoses ${ }^{\mathrm{a}}$} \\
\hline No & $184(99)$ & $44(100)$ & $140(99)$ & 0.429 \\
\hline Yes & $2(1)$ & $0(0)$ & $2(1)$ & \\
\hline \multicolumn{5}{|l|}{ Leakage colo-anal anastomosis ${ }^{\mathrm{a}}$} \\
\hline No & $20(91)$ & $1(100)$ & $19(91)$ & 0.746 \\
\hline Yes & $2(9)$ & $0(0)$ & $2(9)$ & \\
\hline
\end{tabular}

NA: Not applicable. Percentages may not add up to $100 \%$ due to rounding.

a Percentage of anastomotic leakage is calculated of patients in which a specific anastomosis was performed.

found (40\% vs. $19 \%$, respectively, p < 0.01) [12]. In the present study, a postoperative ileus was observed significantly more often in patients with an ileal conduit compared to patients with a colon conduit ( $21 \%$ vs $7 \%, \mathrm{p}=0.024)$. Prolonged duration of ileus is a known complication after formation of an ileal conduit and may lead to a prolonged hospitalization $[8,18]$. In CZE, patients are frequently transferred to referring hospitals when they are clinically stable. This may have led to an underestimation of the hospital stay in patients treated in the CZE.

The proportion of patients with a wound infection (abdominal and/or perineal) was significantly higher in patients with a colon conduit. Several factors may influence wound healing such as surgical approach, extent of surgery, perineal or abdominal reconstruction (i.e. muscle flap reconstruction, omentoplasty), patient characteristics or even bacterial load from the conduit. This could not be explained clearly with the available data and multivariate analysis no longer showed a significant difference between groups.

Despite the possible favorable outcomes in terms of complications, and the fact that previous studies showed a low tie can be safely performed regarding oncological outcomes, a colon conduit is not always technically possible to perform [19,20]. For example, in case of macroscopic lymph node metastasis above the level of the left colic artery a high tie must be performed and a colon conduit can only be created when the blood supply via the middle colic artery and Riolan's arcade conduit is sufficient. Furthermore, in patients with LRRC a repeated resection of the descending colon can result in insufficient length and blood supply for the creation of a colon conduit.

In addition to an ileal or colon conduit, the formation of other types of urinary diversion such as an Indiana pouch, neobladder or double-barrelled wet colostomy are technically possible as well. However, in CZE and EMC reconstructions using an Indiana pouch or neobladder are not performed in patients with extensive colorectal malignancy as these reconstructions are associated with a higher complication rate in these patients [17]. The doublebarrelled wet colostomy (DBWC) inherently has a benefit over the ileal or colon conduit, as it requires only one stoma. However, in our experience this type of diversion is unpleasant to take care of for patients and subsequently has a negative impact on the quality of life. Therefore, a DBWC is not performed in our institutions.
This study is limited by its retrospective nature. Improvement in multimodality treatment such as neoadjuvant therapies over the last decades may influence our results, but the majority of patients in our study were treated with neoadjuvant (chemo-)radiotherapy and there was no significant difference between both groups. Although treatment protocols are similar in both hospitals, there is an imbalance in the proportion of patients with an ileal or colon conduit, as CZE only performed one colon conduit. Also, the admission of IORT is different in both hospitals; in CZE IOERT is administered whereas in EMC IOBT is administered. The significant difference in operation time between the ileal and colon conduit may be explained by the administration of mainly IOBT in the colon conduit group, as this is a more time-consuming procedure than IOERT. For the same reason, IOBT was only applied in case of positive fresh frozen sections, whereas IOERT was also administered in case of clinically threatened margins. Since a larger proportion of patients in this cohort was treated in the CZE where an ileal conduit was the preferred method, IORT was most frequently used in patients with an ileal conduit.

The use of an intestinal segment as urinary conduit may lead to metabolic changes, which may depend on the length and type of the conduit, ileal or colonic $[8,14,21]$. In the literature, a colon conduit is more often associated with metabolic acidosis than an ileal conduit. This study did not find a significant difference, although metabolic acidosis may be underreported.

Long-term follow-up was available in $70 \%$ of the patients with a wide range of follow-up time. Despite these limitations, this study still provides valuable information for the use of both an ileal and colon conduit.

\section{Conclusion}

The formation of an ileal or colon conduit in patients undergoing total pelvic exenteration for LARC or LRRC has similar urologic complications. However, the formation of a colon conduit rules out ileo-ileal anastomotic leakage. Besides, an ileus was more frequently seen after the formation of an ileal conduit in this study. Therefore, the colon conduit may be a feasible alternative for an ileal conduit in patients receiving an end colostomy. 


\section{Declaration of competing interest}

None.

\section{CRediT authorship contribution statement}

J.A.W. Hagemans: Conceptualization, Methodology, Investigation, Formal analysis, Writing - original draft, Writing - review \& editing. E.L.K. Voogt: Conceptualization, Methodology, Investigation, Formal analysis, Writing - original draft, Writing - review \& editing. J. Rothbarth: Methodology, Resources, Writing - review \& editing. G.A.P. Nieuwenhuijzen: Resources, Writing - review \& editing. W.J. Kirkels: Writing - review \& editing. J.L. Boormans: Writing - review \& editing. E.L. Koldewijn: Writing - review \& editing. R. Richardson: Writing - review \& editing. C. Verhoef: Conceptualization, Methodology, Resources, Writing - review \& editing. H.J.T. Rutten: Methodology, Resources, Writing - review \& editing. J.W.A. Burger: Conceptualization, Methodology, Resources, Writing - review \& editing, Supervision.

\section{Acknowledgements}

None.

\section{Appendix A. Supplementary data}

Supplementary data to this article can be found online at https://doi.org/10.1016/j.ejso.2020.02.021.

\section{References}

[1] Gérard JP, Conroy T, Bonnetain F, Bouché O, Chapet O, Closon-Dejardin MT, et al. Preoperative radiotherapy with or without concurrent fluorouracil and leucovorin in T3-4 rectal cancers: results of FFCD 9203. J Clin Oncol 2006;24(28):4620-5.

[2] van GW, Marijnen CAM, Nagtegaal ID, Kranenbarg EMK, Putter H, Wiggers T, et al. Preoperative radiotherapy combined with total mesorectal excision for resectable rectal cancer: 12-year follow-up of the multicentre, randomised controlled TME trial. Lancet Oncol 2011;12(6):575-82. https://doi.org/ 10.1016/S1470-2045(11)70097-3. Available from: http://www.ncbi.nlm.nih. gov/pubmed/21596621.

[3] Arnold M, Sierra MS, Laversanne M, Soerjomataram I, Jemal A, Bray F. Global patterns and trends in colorectal cancer incidence and mortality. Gut
2017;66(4):683-91.

[4] PelvEx Collaborative. Surgical and survival outcomes following pelvic exenteration for locally advanced primary rectal cancer. Ann Surg 2019;269(2): 315-21. https://doi.org/10.1097/SLA.0000000000002528.

[5] PelvEx Collaborative. Factors affecting outcomes following pelvic exenteration for locally recurrent rectal cancer. Br J Surg 2018;105:650-7.

[6] Russo P, Ravindran B, Katz J, Paty P, Guillem J, Cohen AM. Urinary diversion after total pelvic exenteration for rectal cancer. Ann Surg Oncol 1999;6(8): $732-8$.

[7] Fujisawa M, Nakamura T, Ohno M, Miyazaki J, Arakawa S, Haraguchi T, et al. Surgical management of the urinary tract in patients with locally advanced colorectal cancer. Urology 2002;60(6):650-7.

[8] Nieuwenhuijzen JA, de Vries RR, Bex A, van der Poel HG, Meinhardt $W$, Antonini $\mathrm{N}$, et al. Urinary diversions after cystectomy: the association of clinical factors, complications and functional results of four different diversions. Eur Urol 2008;53(4):834-42.

[9] Bricker E. Bladder substitution after pelvic evisceration. Surg Clin 1950;30: 1511.

[10] Schmidt JD, Hawtrey CE, Buchsbaum HJ. Transverse colon conduit: a preferred method of urinary diversion for radiation treated pelvic malignancies. J Urol $1975 ; 113(3): 308-13$

[11] Meijer RP, Mertens LS, Meinhardt W, Verwaal VJ, Dik P, Horenblas S. The colon shuffle: a modified urinary diversion. Eur J Surg Oncol 2015;41(9):1264-8.

[12] Teixeira SC, Ferenschild FT, Solomon MJ, Rodwell L, Harrison JD, Young JM et al. Urological leaks after pelvic exenterations comparing formation of colonic and ileal conduits. Eur J Surg Oncol 2012;38(4):361-6.

[13] Bolmstrand B, Nilsson PJ, Holm T, Buchli C, Palmer G. Patterns of complications following urinary tract reconstruction after multivisceral surgery in colorectal and anal cancer. Eur J Surg Oncol 2018;44(10):1513-7.

14] Roth JD, Koch MO. Metabolic and nutritional consequences of urinary diversion using intestinal segments to reconstruct the urinary tract. Urol Clin North Am 2018;45(1):19-24.

15] Dindo D, Demartines N, Clavien P-A. Classification of surgical complications: a new proposal with evaluation in a cohort of 6336 patients and results of survey. Ann Surg 2004;240(2):205-13.

[16] Brown KGM, Solomon MJ, Latif ER, Koh CE, Vasilaras A, Eisinger D, et al. Urological complications after cystectomy as part of pelvic exenteration are higher than that after cystectomy for primary bladder malignancy. J Surg Oncol 2017;115(3):307-11.

[17] Stotland PK, Moozar K, Cardella JA, Fleshner NE, Sharir S, Smith AJ, et al, Urologic complications of composite resection following combined modality treatment of colorectal cancer. Ann Surg Oncol 2009;16(10):2759-64.

[18] Lee DJ, Tyson MD, Chang SS. Conduit urinary diversion. Urol Clin North Am 2018;45(1):25-36.

[19] Yang Y, Wang G, He J, et al. High tie versus low tie of the inferior mesenteric artery in colorectal cancer: a meta-analysis. Int J Surg 2018;52:20-4.

[20] Fujii S, Ishibe A, Ota M, et al. Randomized clinical trial of high versus low inferior mesenteric artery ligation during anterior resection for rectal cancer. BJS Open 2018;2(4):195-202.

[21] Van der Aa F, Joniau S, Van Den Branden M, Van Poppel H. Metabolic changes after urinary diversion. Adv Urol 2011;2011:764325. 